\title{
Perception of Farmers on Conservation Agriculture for Climate Change Adaptation in Namibia
}

\author{
M. Taapopi ${ }^{1,2}$, J. M. Kamwi ${ }^{3} \&$ N. Siyambango ${ }^{4}$ \\ ${ }^{1}$ Centre for Environmental Management, University of the Free State, 205 Nelson Mandela Dr, Park West, \\ Bloemfontein, 9301, South Africa \\ ${ }^{2}$ Ministry of Agriculture, Water and Forestry, Private Bag 13184, Windhoek, Namibia \\ ${ }^{3}$ Namibia University of Science and Technology, Department of Agriculture and Natural Resource Sciences, \\ Private Bag 13388, Windhoek, Namibia \\ ${ }^{4}$ University of Namibia, Multidisciplinary Research Centre, Private Bag 13301, Windhoek, Namibia \\ Correspondence: N. Siyambango, University of Namibia, Multidisciplinary Research Centre, Private Bag 13301, \\ Windhoek, Namibia. E-mail: nsiyambango@unam.na
}

Received: January 25, 2018

Accepted: February 23, 2018

Online Published: June 20, 2018

doi:10.5539/enrr.v8n3p33

URL: https://doi.org/10.5539/enrr.v8n3p33

\begin{abstract}
Traditional cultivation methods in Namibia are characterised by cultivating the same type of crops persistently on the same piece of land, using a disc or mouldboard plough with minimal to no fertilizer application. This study assessed the knowledge level of farmers' on conservation agriculture and the household factors, which influence farmers to take up conservation agriculture in the Omusati Region of Namibia. Both socioeconomic and biophysical data were collected through household face-to-face interviews from 40 households located in seven constituencies of the Omusati Region. The results showed that technological know-how, limited agricultural inputs and implements for conservation agriculture hindered the uptake of conservation agriculture. In addition, lack of crop residues for mulching purposes and little understanding of the importance of crop rotation were identified as barriers to practice conservation agriculture. Logistic regression analysis showed that age, gender, marital status, education level, crop field size and farming period did not significantly influence the adoption of conservation agriculture. The study indicates that there is a need to encourage the use of climate smart agriculture technologies such as conservation agriculture, which minimizes the negative impacts of dry spells in order to maximize crop production and increase farmers' understanding on the principles of conservation agriculture. Thus, strategies and policies to reduce poverty need to consider local contexts, social norms and values. In this regard, engagement of local farmers and demonstration of the short and long-term benefits of conservation agricultural practices offer promising entry points.
\end{abstract}

\section{Introduction}

In Namibia, as with many countries in Southern Africa, there is a continued and increasing pressure on land resources to raise food production and reduce poverty in rural livelihoods. Additionally, Namibia is the most arid African country south of the Sahara Desert (Ministry of Environment and Tourism, 2011). According to the Namibian National Farmers Union (2008), only 2\% of Namibia's land receives sufficient rainfall for growing crops. Agriculture continues to be a strategic sector in the development, since it forms the backbone of the economy. Although agriculture in Namibia supports $70 \%$ of the population, food security requirements under the current conditions need to address the effects of climate change (Namibian National Farmers Union, 2008).

There are several dimensions to the problem of increased food insecurity; the fundamental cause is declining staple food production in Namibia. The reduced yields of important food crops are attributed to the increase in frequency and intensity of cyclical droughts, the use of rudimentary farming practices and the low input nature of the conventional farming systems in the country (Hase, 2013). This is also coupled with the lack of incentives to farmers for engaging in optimal land management policies that would speed up the need for technological change, leading to low agricultural productivity and consequently increased food insecurity (Ali et al., 2017). Furthermore, very few farmers use farming practices that physically conserve the soil, and as a result, farmers are trapped in a vicious circle of poverty and hunger as the soils continue to degrade unabated. 
Dominant rain-fed crops grown in Namibia include Pennisetum glaucum (pearl millet), Sorghum bicolor (sorghum) and Zea mays (maize). With a $2^{\circ} \mathrm{C}$ increase in temperature and a $10 \%$ reduction in rainfall, the maize yield is expected to experience a reduction of 0.5 tonnes per hectare while subsistence agricultural productivity will decline by $40 \%$ and livestock farm productivity will experience a $50 \%$ reduction (Ministry of Environment and Tourism 2010). The traditional agricultural sector, including subsistence dry-land cropping, suffers the most from climate change (Reid et al., 2007). This will have negative implications on food security and incomes, because livelihoods of Namibians are reliant on climate-sensitive sectors (Reid et al., 2007).

The sustainability of agricultural production and of the continuing provision of environmental services is strongly dependent on maintaining soils in a sufficiently carbon-rich condition. In this case, conservation agriculture (CA) as a production system has the potential to deliver on both sustainability and intensification of agricultural production. Conservation agriculture focuses on three pillars: food security, adaptation and mitigation as it has potential to increase food security and farming system resilience while decreasing greenhouse gas emissions (FAO, 2013). However, few studies have been carried out on the adoption of CA practices in Namibia to increase agricultural productivity. The use of sustainable agricultural practices such as $\mathrm{CA}$, have a huge potential to increase crop yields and at the same time preserve the environment. The aim of this paper was therefore two-fold: (i) to assess the knowledge level of farmers' on CA and (ii) to understand the household factors, which influenced farmers' decisions to take up CA in the Omusati Region of Namibia.

\subsection{Conceptualizing Conservation Agriculture in Northern Namibia}

The Namibian government approach to poverty alleviation aims at addressing the decline in agricultural production while increasing the benefits to the people, particularly smallholder farmers. The Namibian Agricultural policy provides a framework on how farmers can carry out agricultural activities sustainably. Several studies investigating factors of weak adoption of CA have been carried out. These include limited education, limited technical assistance and less financial assistance to farmers (Arslan et al., 2013; Ngoma, et al., 2014). However, if CA programs are to enhance rural livelihood sustainability and resilience to climate change, then local factors towards the adoption of conservation agriculture needs to be understood.

There is little evidence so far of positive yield effects of CA in southern Africa including Namibia, but these reports mainly include experimental plots (Thierfelder \& Wall, 2010; Thierfelder et al., 2015). Caution must be exercised against the belief in CA as a "magic bullet" to a plethora of challenges associated with poor performance of agriculture in sub-Saharan Africa (Cary \& Wilkinson, 1997). A critical analysis about CA's ability to reverse the negative effects of conventional and traditional agricultural practices has for a long time been overlooked (Giller et al., 2009). Literature warns that if CA fails to materialize in tangible benefits that are at the fore of farmers' interest, such as increased food or income, prospects of its widespread adoption are low (Cary \& Wilkinson, 1997).

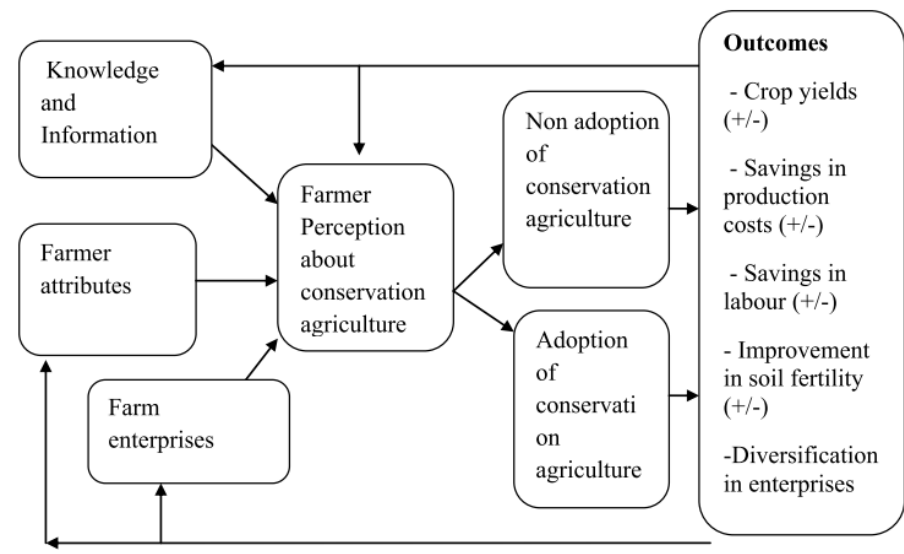

Figure 1. A conceptual framework for CA practices (Source: Mahenge, 2014)

\subsection{Theoretical Framework}

A theoretical framework that provides understanding of the theoretical relationships between important variables and the economic performance of the agricultural practices is depicted in Figure 1. Variables such as knowledge, 
information on agricultural practices and the attributes of the farmers may influence the adoption of CA practices. The perception on CA leads to either uptake or rejection of the CA practices. The adoption of CA practices may lead to increase in crop yields, increase in cost, labour savings, and improvement in soil fertility and diversification of livelihoods. On the other hand, the non-adoption of CA may lead to decrease in crop yields, decrease in profits, decline in soil fertility and non-diversification of livelihoods.

\section{Materials and Methods}

\subsection{Study Area}

The study was carried out in the Omusati Region located in northwest Namibia (Figure 2). Dominant livelihood strategy was used as criteria to select the study constituencies out of the 12 constituencies. All respondents were directly or indirectly dependent on agriculture for their livelihood. Omusati Region has a total area of 26,551 $\mathrm{km}^{2}$ and a total population of approximately 243,166 which grows at an annual rate of 0.6 percent (GRN, 2011). Over 90 percent of the total population live in rural areas. The population census report indicates that there are 46698 registered households in the region with an average of 5.2 persons per household. Omusati Region receives an annual average rainfall between $300-400 \mathrm{~mm}$, which falls during October to April (Mendelsohn, 2002). The soils are typical of arid regions with low fertility due minimal organic matter that is returned to the soil (Mendelssohn et al., 2002). Sandy soils are the major component of the soils in the study area.

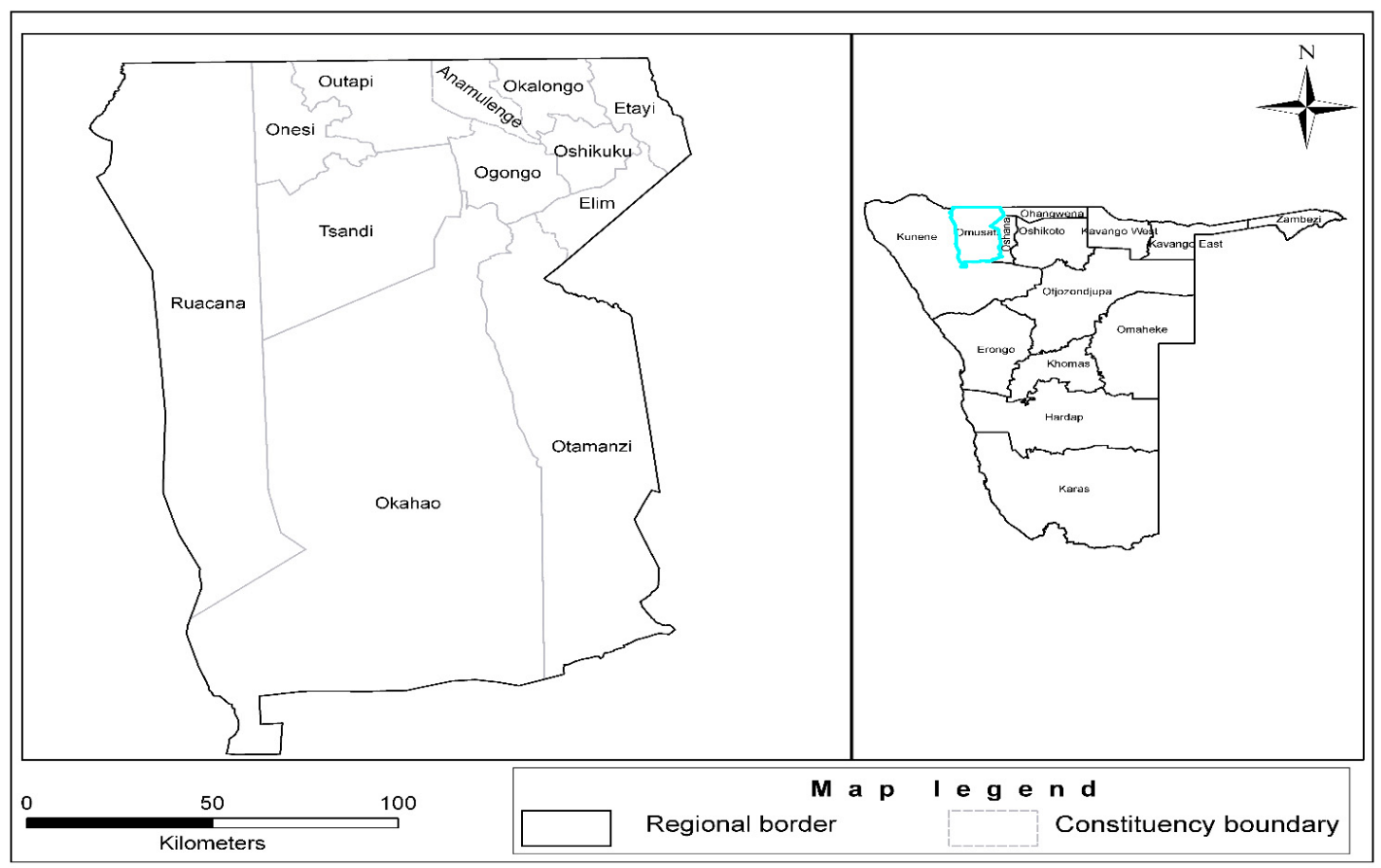

Figure 2. A map of Omusati Region and its constituencies (Source: National Remote Sensing Centre, 2016)

\subsection{Household Questionnaire Design}

Semi-structured questionnaires, which comprised open-ended questions to gather in-depth qualitative data were used. The questionnaires were pretested and revised before the actual interviews of the sampled households. The standardized questionnaire was written in English and was translated into local languages (Ovambo), which were spoken during interviews. Respondents to the survey were not identified either by name or by location to maintain confidentiality. The interviews lasted an average of $45 \mathrm{~min}$. A combination of sampling methods were used in this study. These included random purposeful sampling, criterion purposeful sampling and stratified purposeful sampling strategies. In random and stratified purposeful sampling, samples were drawn from random subset of participant subgroups while in criterion purposeful sampling, specific criteria were sets based on the study to fit a sampled population. Both random and stratified purposeful sampling methods yielded credible results due to a representative population (Blanche et al., 2006). Both men and women headed household farmers 
were considered in the survey. Agricultural Scientific Officers in the extension services and non-governmental organization workers (NGOs) who worked closely with the targeted group of farmers were used to identify CA farmers. An agricultural Research Assistant from Omusati Region was used to assist with the identification of lead farmers. In the Omusati Region there were $61 \mathrm{CA}$ household registered lead farmers who are grouped into six clusters. These farmers were trained by Conservation Agriculture Namibia (CAN) and were registered by the Omusati Farmers' Union. Each cluster was made up of one or two or three constituencies. However, in this study sampling was done per constituency and not per cluster in order to obtain a complete and accurate picture of the information required. A total number of 40 farmers were interviewed of which 31 were CA lead farmers while nine were ordinary farmers who used conventional tillage. A 0.500 Fraction of Probability Proportional to Size Sampling was used to downscale the total number of farmers in the region. Thus, $31 \mathrm{CA}$ farmers interviewed represented $50 \%$ of the total CA farmers in the region taken in seven constituencies.

\subsection{Data Analysis}

The accuracy of the data was checked by frequency counts of each rural household and category. Questionnaire data were processed and coded using the Statistical Package for Social Sciences (SPSS) software version 19 and subjected to further analysis. Descriptive statistics were used to characterize CA and socioeconomic variables. However, in order to identify variables that were independent predictors, which might have influenced the choice of adopting CA, a series of logistic regressions were fitted from which the estimated odds ratios (y) were derived to ascertain the effect of the predictors on CA adoption. In this case, odds ratios were used to measure the magnitude of strength of association or non-independence between two binary data values. The relative importance of a number of predictor variables was quantitatively assessed. It was assumed that a rational rural household would adopt CA based on four mutually exclusive means of adoption, which offered the maximum utility. For each of the adoption options, the household was categorised as either equal to 1 if that household had opted for CA adoption option and 0 if that household had not opted for the CA adoption option. Thus, in a household, the sum of this variable ranged from 0 to 4 , depending on the number of CA adoption predictors indicated. Therefore, each indicator was taken as a binary outcome in which logistic regression was used to model a number of explanatory variables including (1) age; (2) gender; (3) marital status; (4) education level; (5) crop field size and (6) farming period. Dependent variables used for modelling were as follows: (1) climate (yes

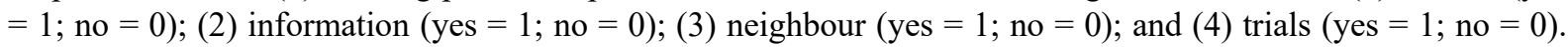
Odds ratio values indicated changes in odds of the adoption of CA upon changes on independent variables (explanatory variables) (Verburg \& Overmars, 2009). The values between 0 and 1 indicated that an increase in the values of independent variables led to a decrease in possibility of the adoption of CA. Contrary to this; values above 1 indicated that an increase in values of independent variables led to an increase in possibility of adoption of CA.

\section{Results}

\subsection{Demographical and Socio-Economical Characteristics of the Sample Population}

The sample survey indicated that $48 \%$ of the respondents were above the age of 55 years while $37.5 \%$ were between the ages of $45-55$. About $15 \%$ of the respondents were aged between $36-45$ years. The gender distribution of farmers indicated that $65 \%$ of the respondents were female. Among the respondents $48 \%$ were married, $23 \%$ widowed, $20 \%$ single and 5\% separated and 3\% divorced and $1 \%$ living together.

\subsection{Crop Farming Preference of Farmers}

Figure 3 shows that all respondents grew Pearl millet (Pennisetum glaucum), Sorghum (Sorghum bicolor), Cowpeas (Vigna unguiculata), Bambara nuts (Vigna subterranea). However, 20 respondents indicated that they also grew Maize (Zea mays) and other crop varieties such as Pumpkins (Cucurbita), Kalahari melon and Water melon (Citrullus lanatus).

The difference in crop yields was measured in tons per hectare $(\mathrm{t} / \mathrm{ha})$ over five years. About $61 \%$ of the respondents recorded an average increase in yields of 1 to 3 tons during the five-year period; $20 \%$ of respondents recorded an increase of 4 to 6 tons while $19 \%$ of the respondents did not notice a difference in yields. Of the farmers who had noticed a change in yield difference, $77 \%$ were satisfied with their crop yield after adopting CA while $23 \%$ were not satisfied. 


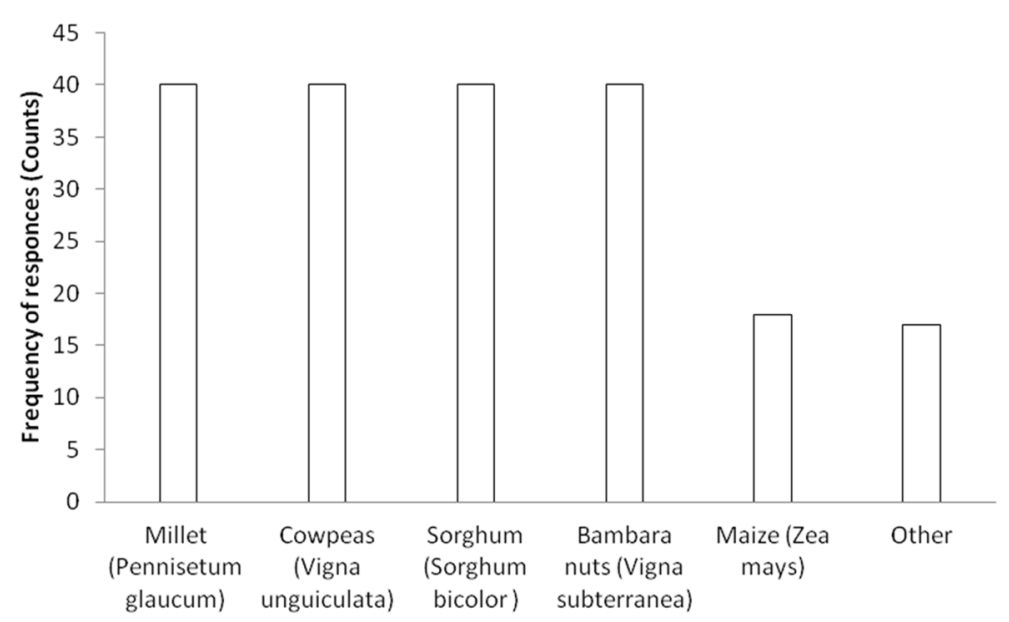

Figure 3. Common crop varieties grown by CA farmers

\subsection{Knowledge of CA among Farmers}

In order to differentiate between conventional farmers (CF) and CA farmers, respondents were asked as to whether they were aware of CA practices. Twenty three percent of respondents among the CF farmers indicated that they were not aware of CA farming while $77 \%$ indicated that they were aware, but not able to practice CA. Respondents were asked to briefly explain how they understood CA and to provide details based on their understanding of the CA concept. This question formed the basis for measuring the knowledge level of farmers on CA. Thirteen respondents $(33 \%)$ understood $\mathrm{CA}$ as a farming practice where ripper was used to break the hard pan and sowing in the furrows.

One of the factors that determined the stability of CA was the number of years in which CA principles were adopted. In this case, farmers were asked to indicate the period that they had been farming using CA guiding principles. Nineteen farmers (48\%) indicated that they had adopted CA for a period of 4-6 years, while 6 farmers $(15 \%)$ had adopted CA for a period of 7-9 years and 6 farmers (15\%) for 1-3 years. Of note is that more females had adopted CA compared to their male counterparts (Figure 4).

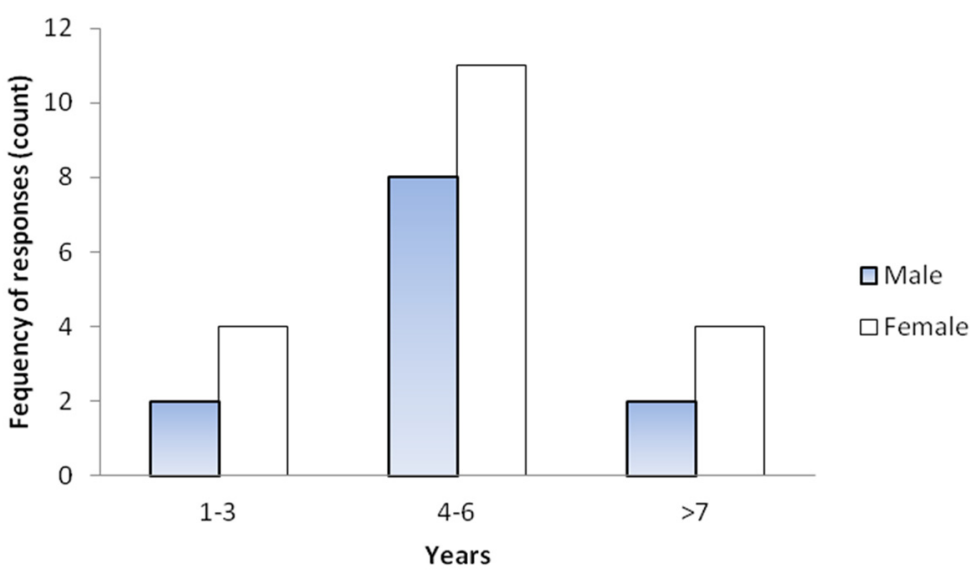

Figure 4. Farming period using CA guidelines

Respondents had to indicate their original source of information about CA (Figure 5). The majority of the farmers were introduced to CA by NGOs, namely CONTILL project and NCAP. This was followed by service providers who mostly owned farm implements such as chisel ploughs and rippers, which were generally used to break the soil hardpan during the transformation stage. The farmer to farmer exchange of knowledge was recorded to be the third influential practice in dissemination of $\mathrm{CA}$ information among farmers. Although agricultural extension officers and media also played a role in CA information dissemination, their impact was outweighed by NGOs and service providers. 


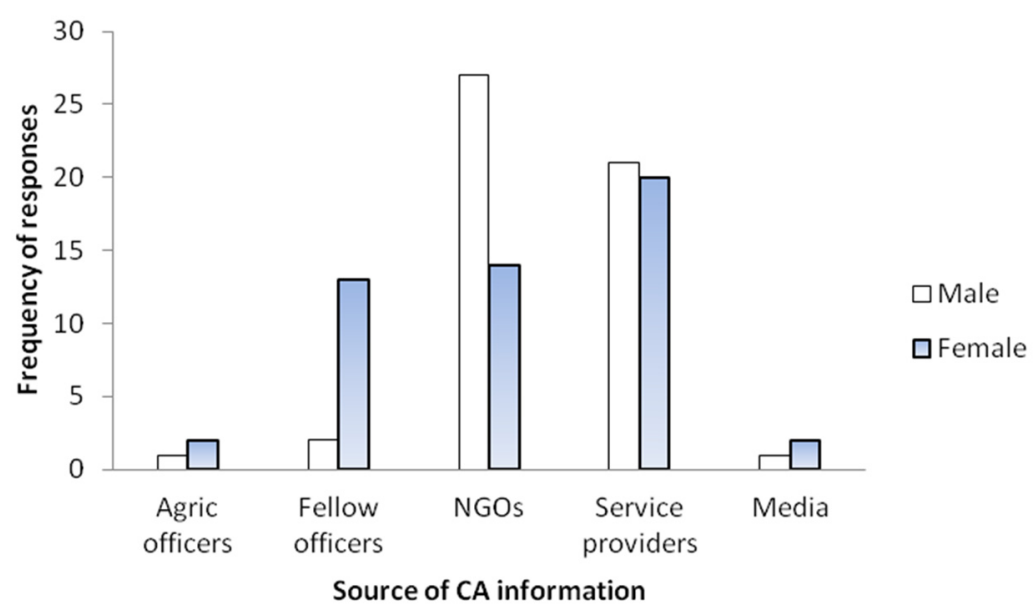

Figure 5. Source of CA information

\subsection{Adoption and Benefits Derived from CA}

One of the objectives of the study was to analyse farmers' opinions on why they incorporated CA practices into their farming systems or not. Figure 6 shows that 14 farmers (35\%) applied CA due to the negative impacts of climate change. However, 10 farmers $(25 \%)$ applied CA, because they copied or learnt the practice from their neighbours. Four farmers $(10 \%)$ based their decision of up-scaling to CA via the literature or trials.

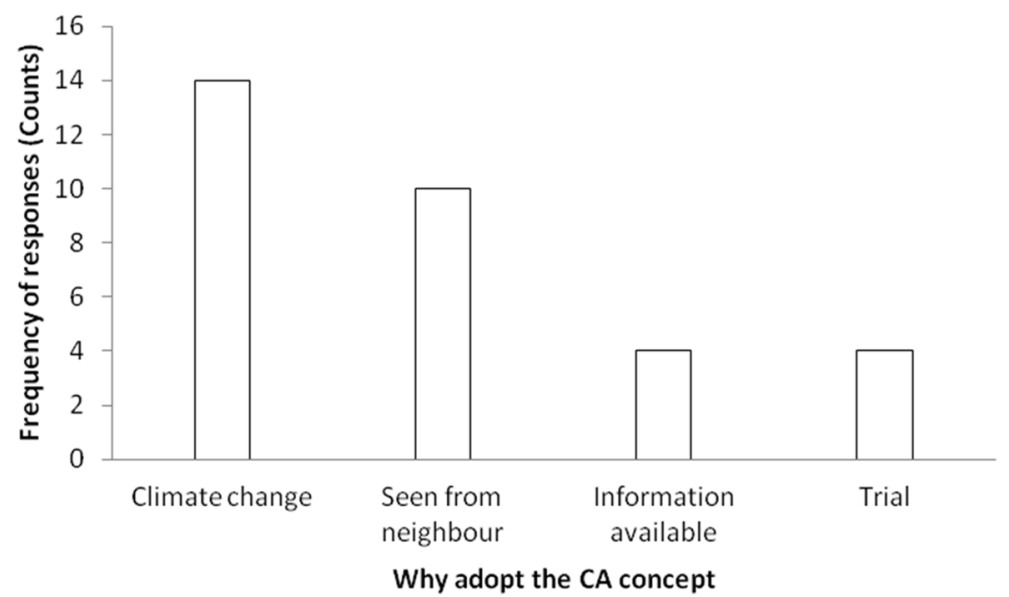

Figure 6. Reasons of changing from $\mathrm{CF}$ to $\mathrm{CA}$

When respondents were asked as to how they applied the three principles of CA, all CA farmers indicated that they always included Vigna unguiculata and Vigna subterranean (legumes) in their crops every season. These were mostly grown as intercropping between the Pearl Millet/Maize or as a small portion in one section of the field, which were interchanged during the following season. Seven CA farmers (18\%) indicated that they kept a quota of stalks from the previous season in the field to use as mulching during the next season. In addition, they also used a ripper for land preparation and only a few used hand-hoes to do direct seeding.

In terms of co-benefits of CA practices (Figure 7), 18 farmers (45\%) indicated that they had noticed improvement in soil structure, easy thinning in crops and improved water infiltration. Eight farmers $(20 \%)$ noticed improved soil moisture while $3(8 \%)$ indicated a reduction in weeds as a result of CA practices. 


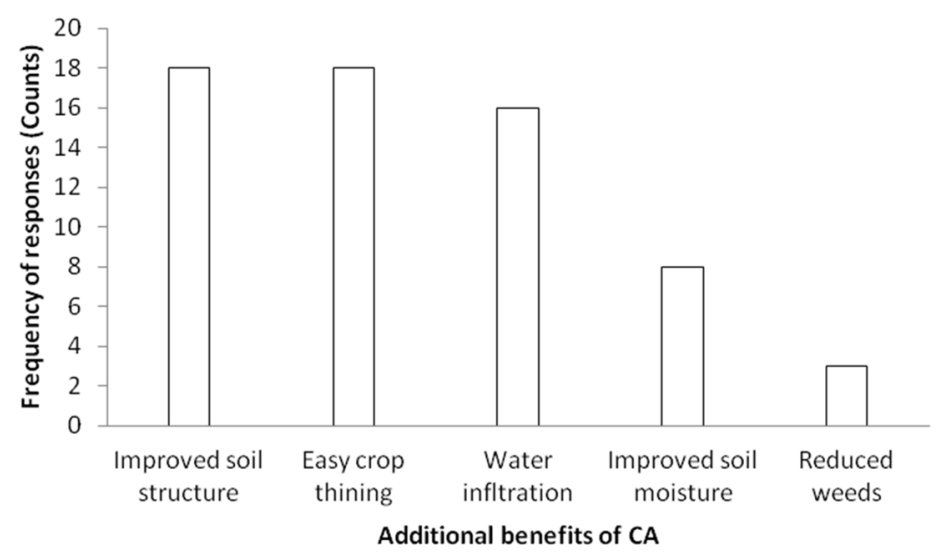

Figure 7. Co-benefits derived from CA practices

A number of limiting factors hinders the adoption of CA practices. In this study, respondents were asked to provide their views on the limiting factors that hamper the uptake of CA by farmers. Lack of knowledge was mentioned by 20 of the respondents $(50 \%)$ to be the most limiting factor followed by lack of incentives such as subsidies and inputs. The lack of farm implements required to perform CA activities was identified by 10 respondents (25\%) (Figure 8). However, 3 respondents ( $8 \%$ ) indicated that CA was labour intensive, particularly during the initial phase.

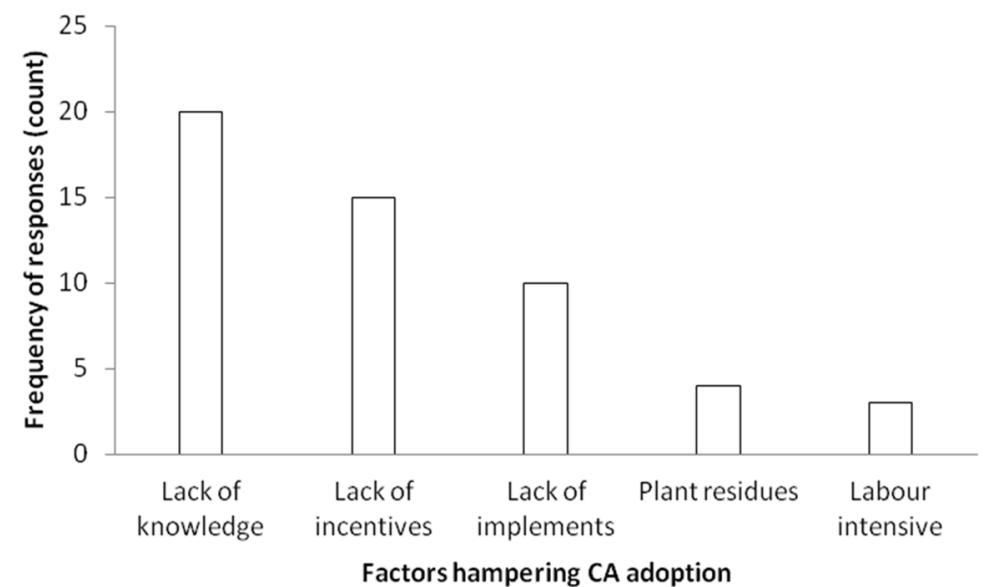

Figure 8. Factors hampering the adoption of $\mathrm{CA}$

Respondents were also asked about the challenges that hindered the adoption of CA including the transformation process from CF to CA. Limited knowledge, which included the technical knowhow on how to apply the CA principles was mentioned. This was followed by the lack of incentives on inputs such as fertilizers, manure, seeds and limited or unavailability of implements for CA operations. Other challenges that were mentioned during the transformation process from $\mathrm{CF}$ to $\mathrm{CA}$ included: weed management, misconception, discouragement by $\mathrm{CF}$ practitioners or farmers who failed at $\mathrm{CA}$ and time management related to $\mathrm{CA}$ activities.

Respondents using CF were asked to state the reasons why they did not use CA. Six respondents indicated that although they had seen the practices of CA from their neighbours, they were aware that CA implements (rippers) were limited and hard to get. Furthermore, four respondents $(10 \%)$ pointed out that CA required greater investment during the initial stages in terms of paying for services such as the use of rippers to break the hardpan. Three respondents $(8 \%)$ indicated that they did not have any knowledge on CA and were therefore not aware of any associated advantages or benefits. 


\subsection{Determinants of CA Adoption by Households}

The results of the logistic regression analysis that influenced the adoption of CA are provided in Table 1 . The output of the logistic regression model revealed that after adjusting for the effect of the factors, there was no significant $(P>0.05)$ influence of all independent variables (age, gender, marital status, education level, crop field size and farming period) on the influence of CA uptake. Despite the absence of significant influences between gender, crop size and the farming period, the odds increased by factors of $1.049,1.845$ and 1.428 respectively on the adoption of CA due to the change of climate. The odds for age, marital status and education level reduced on the adoption of CA due to the change of climate. In terms of the availability of information for CA, the odds for age, gender and education increased by factors of 3.261, 10.905 and 1.473 respectively. Similarly, the odds for age and gender increased by factors of 2.508 and 3.164 for adopting CA as a result of learning from the neighbour. The odds increased for age, education level and crop field size by factors on 3.462, 1.039 and 2.514 for the adoption of CA due to exposure to field trials.

Table 1. Factors affecting the choice of households to pursue CA

\begin{tabular}{llllll}
\hline Dependent variables & Independent variables & $\boldsymbol{P}$-value* & Odds ratio & Lower & Upper \\
\hline \multirow{4}{*}{ Climate } & Age & $\mathbf{0 . 7 1 3}$ & 0.736 & 0.143 & 3.785 \\
& Gender & $\mathbf{0 . 9 5 5}$ & 1.049 & 0.202 & 5.454 \\
& Marital status & $\mathbf{0 . 5 9 7}$ & 0.902 & 0.614 & 1.323 \\
& Education level & $\mathbf{0 . 4 7 5}$ & 0.808 & 0.451 & 1.449 \\
& Crop field size & $\mathbf{0 . 3 2 0}$ & 1.845 & 0.552 & 6.170 \\
& Farming period & $\mathbf{0 . 6 5 9}$ & 1.428 & 0.294 & 6.937 \\
\hline \multirow{4}{*}{ Information } & Age & $\mathbf{0 . 4 0 7}$ & 3.261 & 0.20 & 53.286 \\
& Gender & $\mathbf{0 . 1 8 7}$ & 10.905 & 0.313 & 379.374 \\
& Marital status & $\mathbf{0 . 2 7 4}$ & 0.59 & 0.229 & 1.519 \\
& Education level & $\mathbf{0 . 5 4 3}$ & 1.473 & 0.423 & 5.124 \\
& Crop field size & $\mathbf{0 . 8 4 5}$ & 0.779 & 0.064 & 9.483 \\
& Farming period & $\mathbf{0 . 5 1 5}$ & 0.439 & 0.037 & 5.246 \\
\hline \multirow{5}{*}{ Neighbour } & Age & $\mathbf{0 . 2 6 8}$ & 2.508 & 0.493 & 12.761 \\
& Gender & $\mathbf{0 . 2 2 1}$ & 3.164 & 0.500 & 20.015 \\
& Marital status & $\mathbf{0 . 0 7 7}$ & 0.614 & 0.357 & 1.055 \\
& Education level & $\mathbf{0 . 2 5 3}$ & 0.657 & 0.320 & 1.349 \\
& Crop field size & $\mathbf{0 . 8 2 7}$ & 0.855 & 0.210 & 3.481 \\
& Farming period & $\mathbf{0 . 4 4 0}$ & 0.541 & 0.114 & 2.575 \\
\hline & Age & $\mathbf{0 . 3 1 2}$ & 3.462 & 0.312 & 38.468 \\
& Gender & $\mathbf{0 . 8 8 0}$ & 0.817 & 0.059 & 11.242 \\
& Marital status & $\mathbf{0 . 5 7 3}$ & 0.823 & 0.418 & 1.621 \\
& Education level & $\mathbf{0 . 9 4 1}$ & 1.039 & 0.376 & 2.874 \\
& Crop field size & $\mathbf{0 . 3 3 7}$ & 2.514 & 0.383 & 16.484 \\
& Farming period & $\mathbf{0 . 1 7 1}$ & 0.225 & 0.027 & 1.903 \\
\hline
\end{tabular}

*Significant at $P<0.05$.

\section{Discussion}

\subsection{Demographic and Socio-Economic Characteristics of the Sampled Population}

Although most respondents were married, the results show that women registered as lead farmers and involved in CA activities. Harford et al. (2009), stated that women are more involved in CA as it is regarded as a household activity despite men being regarded as heads of households. The level of education did not play a role in the decision to participate in CA since most lead farmers were from either a low or higher education level. The study, however, suggested that labour force was important in the adoption process of CA. This has also been supported by Harford et al. (2009). Conservation farming requires hard work to obtain a better harvest. The number of household members determines the existence of labour force to work in the field. In this study, the average number of household members was made up of 7-9 people who farmed on an average field size of 4-6 Ha or 7-9 Ha. Although some households indicated to have more than nine members, it was also revealed that 
some of these household members were not at home throughout the year to take part in labour activities, as they were in urban areas in search of employment opportunities. While farmers indicated to have a piece of land for farming purposes, not all farmers utilised the total size of the land i.e. not the whole area indicated is under cultivation. The Communal Land Reform Amendment Act of 2013 (GRN 2013) was also promulgated to ensure registration and fair distribution of land in communal areas therefore reduced oversized pieces of land.

Generally, the benefits of CA are not immediate. Farmers' perception on the benefits of CA is more focused on the increase of crop yields in order to produce more and be able to feed their families. One of the factors that determine the stability of CA and to be able to reap the benefits is the number of years in which CA was adopted. Most (80\%) respondents had adopted CA for a period of between 4-9 years. Of these respondents who had adopted CA confirmed the increase in yield for Pearl millet ranging between 1-3 tons per hectare. Those who applied CA for less than three years did not confirm a satisfactory yield increase. This is in agreement with the FAO (2009), which states that the yield increase in CA is usually detected after three consecutive years after adopting the practice. Despite the yield difference, not all farmers were satisfied. Hence, only $77 \%$ of the farmers who indicated to have noticed the change in yields were satisfied with their crop yields after adopting CA.

Although the main interest of farmers to adopt CA is driven by increase in crop productivity, there are other non-tangible benefits associated with CA. It was interesting to note that farmers listed the advantages of CA as improved soil structure leading to easy and deep penetration of roots. The favourable soil structure led to improved soil fertility, easy thinning in crops, improved water infiltration, water retention on the soil surface, improved soil moisture, reduced weeds, (reduced water runoff and evaporation). Benefits of CA are widely documented by ACT (2012) and FAO (2015). Similar studies such as by Never et al. (2013); Milder et al. (2011) and Palm et al. (2013) have highlighted other benefits of CA other than crop yield improvement, which include energy use, reduction in production costs, improved biological pest control and increase in nutrient availability.

In terms of the sources of information on CA, the majority of the farmers revealed that they were introduced to CA through NGOs, Lima Nawa and NCAP during 2008-2011 and 2012-2015. The same NGOs had assisted the farmers with free ploughing services and free inputs of 1 ha per farmer. A successful farmer can influence others, therefore some farmers indicated that they had copied CA interventions from fellow farmers. As benefits of CA were becoming evident, some lead farmers with a better source of income achieved or managed to procure tractors and implements such as rippers and rented to their counterparts since the demand was high. It was through this process that other farmers learned about CA.

\subsection{Challenges for Adopting $C A$}

A number of limiting factors hinders the adoption of CA and are part and parcel of CA interventions (Mutua et al., 2014). In this study, farmers could recall the challenges they experienced during the transformation process. The same factors were highlighted by CF practitioners as the reasons why they did not partake in CA intervention. These included the lack of knowledge or technical know-how on how to apply the three CA principles, lack of farm implements required to perform CA activities, lack of incentives, poor subsidised services and inputs (fertilizers, manure, seeds), and expensive tillage services using a ripper. Similar challenges were also highlighted by Mazvimavi et al. (2008). The FAO (2009) emphasized that the main obstacle to the slow adoption of CA in Africa is lack of knowledge on how to undertake CA and the associated benefits. Farmers need to acquire the basic knowledge before attempting to try the practices on their own farms (FAO, 2009). Farmers also highlighted challenges such as the lack of weed management, misconception, discouragement by $\mathrm{CF}$ farmers who failed at $\mathrm{CA}$ and time management related to CA activities to be hindering the adoption of CA. There was a need for investment in the promotion of the CA concept among the farming community of the Omusati Region. This meant more awareness creation on CA was required to ensure that the correct information was passed on to farmers and that they applied the concept of CA as per guiding principles. However, this required training, especially on how to manage cover crops. The provision of inputs, farm implements and services at a subsidised cost by the government to any active CA farmer has worked for countries such as Malawi to boost the up-scaling of CA, and therefore, bringing many farmers on board (Dorward \& Chirwa, 2011). This could be recommended for Namibia. The process of CA adoption should include the use of various participatory methods such as farmers' field days, experimental plots, farmers exchange visits, exposure visits and training of trainers among others.

The objectives of CA can be achieved through the application of the three principles in combination with good agricultural practices. However, the FAO (2009) stated that farmers find it difficult to divide the plant residues between CA and fodder for their livestock in times of drought. Hence, most farmers would opt to use the plant residues as fodder over CA as mulching materials. Although the use of planting basins to sow seeds is supported 
by many organisations such as FAO and ACT, farmers who participated in this study did not practice this due to the excessive growth of weeds.

\subsection{Conclusions and Outlook}

The study revealed the role of CA practices in the farming systems of northern Namibia. Farmers were aware of the benefits associated with CA, but had minimal knowledge on how to effectively employ CA practices. Farmers seemed to be more interested in yield improvement than the aspects of environmental management. However, a change in attitude towards sustainable agriculture land management was noticed among the CA farmers due to a reduction in using agricultural practices that posed threat to the environment. The lack of availability and affordability of equipment, ploughing services, agricultural inputs such as seeds, manure, and fertilizer were identified to be major constraints for farmers to adopt CA. This resulted in perception for most farmers, both CA and CF to consider the use of a ripper as the main component of CA application. In this case, most CA farmers did not apply all the principles of CA. In addition, lack of training and capital to invest in new technologies also limited the up-scaling of CA concept in the region. Limited access to farm implements and expensive hiring services of implements forms part of implement related challenges.

The inclusion of various stakeholders such as local authorities (Regional Governors and Councillors), environmental agencies, farmers organizations, government ministries such as the Ministry of Environment and Tourism, equipment and farm input manufacturer and input suppliers, agricultural change agents at both regional and village levels in the promotion of CA should be encouraged as they are the most influential and people on the ground. Establishment of Farmer organizations such as Savings and Credit Co-operative Society (SACCOS) should be explored to help farmers by bringing farm inputs such as fertilizers, pesticides and seeds closer to the farmers thereby making them easily accessible. The adoption of CA technologies should not only look at the economic importance, but also its socio-economic importance of the local people. For example, there should be some form of incentive. By awarding top performing farmers might encourage the adoption of CA. Finally, there is a need for on-going research on CA such as on drought resistant crop varieties that can be adapted to climate changes and cover crops suitable in the study areas or other parts of Namibia with a similar set of environmental conditions.

\section{References}

ACT. (2012). Gender Integration in Conservation Agriculture. Kenya: ACT. Retrieved from http://abaco. act-africa.org/?wpfb_dl=37.

Ali, S., Liu, Y., Ishaq, M., Shah, T., Abdullah., Ilyas, A., \& Din, I. (2017). Climate Change and Its Impact on the Yield of Major Food Crops: Evidence from Pakistan. Foods, 6, 39. https://doi.org/10.3390/foods6060039

Arslan, A., McCarthy, N., Lipper, L., Asfaw, S., \& Cattaneo, A. (2013). Adoption and Intensity of Adoption of Conservation Farming Practices in Zambia. IAPRI Working Paper No. 71. Lusaka, Zambia.

Blanche, M. T., Durrheim, K., \& Painter, D. (2006). Research in Practice: Applied Methods for the Social Sciences. Cape Town: UCT Press.

Cary, J. W., \& Wilkinson, R. L. (1997). Perceived profitability and farmers 'conservation behaviour. Journal of Agricultural Economics, 48(1-3), 13-21. https://doi.org/10.1111/j.1477-9552.1997.tb01127.x

Dorward, A., \& Chirwa, E. (2011). The Malawi Agricultural Input Subsidy Programme: 2005-6 to 2008-9. Forthcoming (after further editing). International Journal of Agricultural Sustainability (IJAS), 9(1).

FAO. (2009). Scaling-up Conservation Agriculture in Africa: Strategy and Approaches. The FAO Sub-regional Office for Eastern Africa. Addis Ababa. Retrieved June 12, 2016, from http://www.fao.org

FAO. (2013). Climate Smart Agriculture: Source Book. Retrieved November 1, 2016, from www.fao.org/publications

FAO. (2015). Conservation Agriculture. Retrieved October 12, 2016, from http://www.fao.org/ag/ca/4.html

Giller, K. E., Witter, E., Corbeels, M., \& Tittonell, P. (2009). Conservation agriculture and smallholder farming in Africa: the heretics' view. Field Crops Research, 114(1), 23-34. https://doi.org/10.1016/j.fcr.2009. 06.017

GRN. (2011). Omusati 2011 Census Regional Profile. Windhoek: Namibia Statistics Agency (NSA).

GRN. (2013). Promulgation of Communal Land Reform Amendment Act, 2013 (Act No. 13 of 2013). Windhoek: Namibia. Government Gazette. 
Harford, N., Le Breton, J., \& Oldreive, B. (2009). Farming for the Future: A Guide to Conservation Agriculture in Zimbabwe. Harare: Zimbabwe Conservation Agriculture Task Force.

Hase, F. (2013). Facilitating Conservation Agriculture in Namibia through Understanding Farmers' Planned Behaviour and Decision Making (MSc Thesis, Swedish University of Agricultural Sciences).

Mahenge, J. (2014). A comparative Economic Analysis of Convention Agricultural Practices in Southern Uluguru Mountains, Morogoro, Tanzania (MSc Thesis).

Mazvimavi, K., Twomlow, S., Belder, P., \& Hove, L. (2008). An Assessment of the Sustainable Uptake of Conservation Farming in Zimbabwe. Bulawayo: International Crops Research Institute for the Semi-arid Tropics (ICRISAT).

Mendelsohn, J., Jarvis, A., Roberts C., \& Robertson, T. (2002). Atlas of Namibia. Cape Town. David Philip Publisher.

Milder, J. C., Majanen, T., \& Scherr, S. J. (2011). Performance and Potential of Conservation Agriculture for Climate Change Adaptation and Mitigation for Sub-Saharan Africa. Eco Agriculture Partners. Retrieved June 14, 2016, from ecoagriculture.org/publication

Ministry of Environment and Tourism. (2011). Fourth National Report to the Convention on Biological Diversity. Windhoek, Namibia.

Mutua J., Muriuki, J., Gachie, P., Bourne, M., \& Capis, J. (2014). Conservation Agriculture with Trees: Principles and Practice. Nairobi: World Agroforestry Centre.

Namibian National Farmers Union. (2008). Retrieved from www.nnfu.org.na/

National Remote Sensing Centre. (2016). A map of Omusati Region and the Constituencies. Ministry of Agriculture, Water and Forestry (MAWF). Windhoek: Directorate of Forestry.

Never, M., Nyeverwai, G., Dadirayi, M., Vincent, M., Maponga, T. G., \& Edgar, M. (2013). Adoption of the "Conservation Farming" practice in maize production by small holder farmers in the Makoni District of Zimbabwe. International NGO Academic Journal, 9, 1-10.

Ngoma, H., Mulenga, B. P., \& Jayne, T. S. (2014). What Explains Minimal Usage of Minimum Tillage Practices in Zambia? Evidence from District-Representative Data. IAPRI Working Paper No. 82. Lusaka, Zambia: IAPRI.

Palm, C., Blanco-Canqui, H., Deklerck, F., Gatere, L., \& Grace, P. (2013). Conservation agriculture and ecosystem services: An overview. Journal of Agriculture, Ecosystem and Environment, 187, 87-105.

Reid, H., Sahlén, L., MacGregor, J., \& Stage, J. (2007). The economic impact of climate change in Namibia: How climate change will affect the contribution of Namibia's natural resources to its economy. Environmental Economics Programme Discussion Paper 07-02. International Institute for Environment and Development, London.

Thierfelder, C., \& Wall, P. (2010). Investigating conservation agriculture (CA) systems in Zambia and Zimbabwe to mitigate future effects of climate change. Journal of Crop Improvement, 24(2), 113-21. https://doi.org/10.1080/15427520903558484

Thierfelder, C., Matemba-Mutasa, R., \& Rusinamhodzi, L. (2015). Yield response of maize (Zea mays L.) to conservation agriculture cropping system in southern Africa. Soil Tillage Research, 146, 230-242. https://doi.org/10.1016/j.still.2014.10.015.

Verburg, P. H., \& Overmars, K. P. (2009). Combining Top-down and Bottom-up Dynamics in Land Use Modelling: Exploring the Future of Abandoned Farmlands in Europe with the Dyna-CLUE model. Landscape Ecology.

\section{Copyrights}

Copyright for this article is retained by the author(s), with first publication rights granted to the journal.

This is an open-access article distributed under the terms and conditions of the Creative Commons Attribution license (http://creativecommons.org/licenses/by/4.0/). 